\title{
The Use of a Citizen Leader Model for Teaching Strategic Leadership
}

\author{
Christine A. Langone \\ Professor, Agricultural Leadership, Education, and Communication \\ 112 Four Towers \\ University of Georgia \\ Athens, GA \\ clangone@uga.edu
}

\begin{abstract}
Strategic leadership is perhaps the area where undergraduate students have the least experience. Therefore, a focus on developing these skills is critical for college-level leadership educators. Teaching strategic leadership requires that educators design programs that make explicit, direct, and formal links between theory and practical experience, opportunity to reflect, solve problems, work in teams, and engage in active learning.

The Citizen Leader Model (CLM) for student engagement goes beyond volunteerism and service learning through its focus on bringing about substantive change in organizations and communities. This article describes a teaching method for teaching strategic leadership using the CLM, sample projects, and outcomes.
\end{abstract}

\section{Introduction}

Strategic leadership is a critical leadership skill, yet one in which undergraduate students typically have little experience. Additionally, effective leadership education challenges faculty to engage students in real life environments in which to apply and practice skills. This article presents a model for teaching Strategic Leadership through a Citizen Leader project approach in an undergraduate leadership development course designed to enhance students ability to bring about change.

\section{Educating for Strategic Leadership}

Current models of leadership focus on working in teams to create real change (Daft, 2002; Nanus \& Dobbs, 1999). For example, Rost s (1991) definition of leadership states that leadership is an influence relationship among leaders and followers who intend real changes and outcomes that reflect their shared purposes (p. 102). Strategic leadership refers to setting future direction for an organization 
or group. It involves looking at the environment and the organization s mission or purpose and making decisions about which visions, activities, and goals to pursue.

Strategic leadership requires high level cognitive skills which include systems thinking, creative problem solving, gathering and managing input from multiple sources, risk tolerance, and the ability to create a vision of the future. Students must learn through their educational experience to deal with complex organizational and societal issues, often requiring thought and collaboration outside the boundaries of a particular discipline or their previous knowledge and experience (Langone, 2000). Recently, several recommendations have encouraged educators to design programs that make explicit, direct and formal links between theory and practical experience, opportunity to reflect, solve problems, work in teams, and engage in active learning experiences (The Boyer Commission on Educating Undergraduates in the Research University, 1998; Morrill \& Roush, 1991). This type of learning environment and philosophy is especially useful in developing strategic leadership.

\section{The Citizen Leader Model}

One method for teaching strategic leadership is through the use of the Citizen Leader Model of community service described by Perreault (1994). The Citizen Leader Model goes beyond volunteerism and service learning through its focus on student engagement in substantive change in their organizations and communities. Citizen Leadership is both a vehicle allowing students to translate theory into practice and an orientation toward community change in which students become change agents creating a better future. It connects students to their communities or organizations, provides practical application of knowledge, and creates synergy among students, communities, and society to solve common problems through long-term change.

As Citizen Leaders, students become active citizens (Perreault, 1994) who help define problems and work with clients or organizations to solve these problems. Rather than merely addressing short-term needs (e.g., collecting food for a food bank), students look for causes to the issue and seek long-term solutions.

By implementing the CLM as a tool for learning strategic leadership, students connect to their community through investigation of issues, targeting needs, and developing strategies to solve problems as members of their community. To implement the model students first study concepts of strategic leadership, environmental scanning and information management, needs assessment, and prioritizing issues using tools such as the SWOT (strengths, weaknesses, opportunities, threats) assessment (Choo, 1999; Daft, 2002; Gorski, 1991).

\section{Needs Assessment and SWOT Analysis}


SWOT analysis is a method of looking at an organization or community's internal Strengths (S) and Weaknesses (W) and the external Opportunities (O) and Threats (T) posed by its environment or outside forces (Daft, 2002; Gorski, 1999). This tool can give a candid idea of internal and external facts, perceptions, trends or opinions. SWOT analysis can help an organization or community in its planning by identifying areas that need to be changed or stimulating ideas about new services, products or programs.

For undergraduate students the SWOT analysis tool provides a clear, organized method for investigating and reporting the myriad aspects that make up an organization or community. The tool is useful for team use as it allows ready communication among team members or division of tasks. It provides concrete steps and categories, which can be easily explained.

In order to assist students in learning this procedure, a community needs assessment exercise was developed for class use. Using a set of newspaper articles a simulated community was created that students use as the basis for assessing community needs, assets, and opportunities. Approximately 15 newspaper articles on varying issues were compiled. Students review each issue and categorize it in the SWOT framework. For example, the issue of solid waste disposal might be classified as a Threat while articles on the local symphony and volunteer awards for community involvement highlight the positive aspects or Strengths of the community. Similar exercises can be developed based on an organization or campus community. Another option is to use the campus newspaper as an indicator of the school environment.

In discussing the outcomes of the exercise, students come to realize that some issues might be considered in more than one category and that individual and community values play a role in determining the picture of the community. Additionally, different groups will each have a different picture of the community depending on their focus, point of view, and the makeup of the group.

\section{Applying Citizen Leadership to Strategic Leadership}

By combining key ideas of strategic leadership with the Citizen Leader model, the students design, implement, and evaluate a team-based community service project as one of the course requirements. This project is designed to encourage students to use their skills in communication, team building, and most importantly, strategic leadership. The following sections outline the project.

\section{- Conducting the Community SWOT Assessment}

Teams first conduct a needs assessment using the SWOT technique based on the local community. Students can define what community" they choose as long as all team members are members of the community. For example, the local geographic community may be used only if all team members reside in the 
community. Teams typically use the geographic community, but some choose neighboring counties (if they live there) or the campus community.

- Researching the Issue

Students then conduct background research to develop a full understanding of the problem or issue. For example, in recognizing that an area food bank needs food and volunteers to distribute food, students investigate causes of hunger. Topics might include the effects of the economy on low income households, problems with minimum wage laws, lack of affordable housing, or high cost of medical insurance and care, all of which might contribute to families not having sufficient financial resources to support themselves. The research provides the basis for understanding the problem and needed action. It should provide a clear, logical rationale for the vision, goals, and subsequent action.

\section{- Creating a Vision and Action Plan}

Based on needs analysis and background research, teams pinpoint a key issue, then formulate vision and goals, and plan and implement a project to address this issue. This process involves understanding the concept of today s communities and organizations, resource development, project planning and implementation.

While teams are not expected to reach their vision, it should provide a useful guide or sense of direction for continued action. The specific team goals for action should realistically be accomplished within the eight week project period. The goals should follow logically from the stated vision and be specific and achievable. Project planning strategies are used to design the action plan and time line needed to achieve the team goals. Students then implement the project, documenting team efforts (meetings, the actual setting for project, team members at work, etc.). Digital cameras are made available for check-out so that teams can provide visual documentation of their activities.

- Evaluation and Reflection

Evaluation and reflection are critical to the learning process. Reflection is the process of stepping back from the process or action to ask oneself what has happened and the meaning of the action and results (Komives, Lucas, \& McMahon, 1998). Students consider questions such as:

- Did you reach your goals?

- What helped or hindered reaching the goals (either related to team process, the task or other factors)?

- If you were to do this project again, what, if anything, would you do differently?

- With changes, is the project worth doing again?

- How were the recipients or clients of your work affected?

- How do you know? 
- What impact did your efforts have?

- How did working as a team effect the impact (as contrasted an individual acting alone)?

- How might the impact be increased?

- What people, resources, time, effort, etc., would be needed?

Through evaluation and critical reflection of the process, program, team process, and individual member contributions, students internalize strategic leadership concepts, and learn from the experience while providing valuable service to their community.

\section{Student Projects}

Students target an array of issues based on the identified needs and their own interests and skills. Following are just a few examples of the issues and projects student teams have conducted over the past three years:

- Senior Citizen Care: Addressed needs related to nutrition and loneliness: (a) volunteered to deliver meals with Meals on Wheels; (b) solicited donations of fruit from local grocery stores and delivered packages to a nursing home combined with a visit with residents; and, (c) visited a senior day care facility with planned activities and companionship.

- Political Reform: Collaborated with student government leaders to plan and present a forum on the electoral college after the 2000 presidential election.

- Children with Disabilities: Prepared educational materials for blind children that were delivered to a children's hospital.

- Environmental issues: Supported efforts of local nature center and park through trail maintenance and construction.

- Historic Preservation: Painting and maintenance on an antebellum mansion.

- Homelessness and Hunger: Prepared a Thanksgiving meal for a needy family, supplied meals at a local homeless shelter, and conducted a food drive to contribute to local food bank.

- Health Care: Did fund raising as volunteers to support Relay for Life, a major fund raising and educational effort of the American Cancer Society.

Although the community environment is the basis for this project, an important focus is on the application to business and organizational environments. Students realize the importance of applying the same critical thinking and reflection skills in a variety of arenas.

\section{Student Reaction to the Experience}

While students are increasingly becoming involved in service activities, most find this comprehensive approach interesting and rewarding. They now see the application of leadership skills and the broader context of issues in communities and organizations. For other students, this project is their first effort at service and 
citizen leadership. Representative student comments demonstrate the impact of the project on their personal and leadership development:

- The community service project effectively taught many leadership skills such as team work, responsibility, innovation, etc.

- The project helped me grow in that I felt like I had accomplished something when I left the school. I faced several situations I didn't know how to handle...It gave me a chance to use my problem-solving skills. The project made me feel we had made a difference in the kid's lives. (Elementary AfterSchool Olympics)

- This project definitely helped me to grow as an individual, leader, and citizen....taught me that each member of the group, whether a leader or follower, is just as important as everyone else. I learned to take criticism as a positive tool towards helping myself be more effective. (Humane Society Fundraiser)

\section{Summary}

Strategic leadership is a critical leadership skill, and one in which leadership educators can foster learning and practical application. When combined with the CLM for addressing community issues, students develop a comprehensive set of skills in creating a vision, project planning, communication, teamwork, and personal leadership skills.

\section{References}

Boyer Commission (1998). Reinventing undergraduate education: A blueprint for America s research universities. Stony Brook, NY: State University of New York at Stony Brook for the Carnegie Foundation for the Advancement of Teaching.

Choo, C. W. (1999). Information seeking and finding - the art of scanning the environment. Bulletin of the American Society for Information Science, 25 (3), 21-24.

Daft, R. L. (2002). The leadership experience. $2^{\text {nd }}$ ed. NY: Harcourt College Publishers.

Gorski, S. E . (1991). The SWOT team approach: Focusing on minorities. Community, Technical, and Junior College Journal, 61, (3), 30-33.

Komives, S. R., Lucas, N., \& Nance, T. R. (1998). Exploring leadership: For college students who want to make a difference. San Francisco: Jossey-Bass.

Langone, C. A. (2000). Leadership and service: Engaging students in community. Paper Presented to the Experiential Learning Conference, California State University, Fresno, September 28-29. 
Morrill, R., \& Roush, J. (1991). Leadership education: A new threshold. Phi Kappa Phi Journal, 71(1), 26-28.

Nanus, B., \& Dobbs, S. M. (1999). Leaders who make a difference. San Francisco: Jossey-Bass.

Perreault, G. (1994). Citizen Leader - A community service option for leadership students. In Building Leadership Connections, Proceedings of the Association of Leadership Educators Conference, p. 229-240.

Rost, J. C. (1991). Leadership for the twenty-first century. NY: Praeger. 